Om noen store sykehus skulle ha ønske om å ansette leger med bred erfaring og akuttmedisinsk kompetanse er jo dette helt greit, men det er ikke det samme som å innføre en ny medisinsk spesialitet (3). La oss heller utvikle, evaluere og forbedre pasientforløpene, i stedet for å bruke ressurser på en ny spesialitet det ikke er behov for.

\section{Guttorm Brattebo}

guttorm.brattebo@helse-bergen.no

Guttorm Brattebø (f. 1961) er Avdelingsoverlege/-sjef ved Akuttmedisinsk avdeling KSK, Haukeland Universitetssykehus.

Ingen oppgitte interessekonflikter.

\section{Litteratur}

1. Bjørnsen LP, Uleberg O. Akuttmottaket trenger egne spesialister. Tidsskr Nor Legeforen 2015; 135: 1230-2.

2. Bjørnsen LP. Uleberg 0 . Kompetanseplan for akuttmedisinsk fagområde i Norge. Oslo: Norsk selskap for akuttmedisin, 2012. www.norsem.no (29.8.2015).

3. Bjelke C, Breidablikk HJ, Johansen K et al. Utredning av en evt. ny spesialitet i akuttmedisin - et interregionalt prosjekt. Bodø: Helse Nord, 2008.

\section{Re: Tusen takk for meg}

Hege Gjessing har som president i Legeforeningen vært en betydningsfull bidragsyter i arbeidet med å etablere en egen spesialitet $i$ rus- og avhengighetsmedisin. Jeg vil takke den avtroppende presidenten (1) for at hun alltid har vært tilgjengelig og for den tilliten hun har vist oss i Norsk forening for rus- og avhengighetsmedisin (NFRAM). Vi føler at vi har fătt representere Legeforeningen i mange sammenhenger. Det har vært viktig i synliggjøringen av det rusmedisinske fagfeltet.

\section{Guri Spilhaug}

guri@spilhaug.net

Guri Spilhaug (f. 1954) er leder av Norsk forening for rus- og avhengighetsmedisin (NFRAM) og lege ved Oslo universitetssykehus. Ingen oppgitte interessekonflikter.

\section{Litteratur}

Gjessing H. Tusen takk for meg. Tidsskr Nor Legeforen 2015; 135: 1411.

\section{RETTELSER}

Kronisk lymfatisk leukemi i Norge -

insidens og prognose ved diagnosetidspunktet

Geir E. Tjønnfjord, Bernt E. Ly, Tom Børge Johannesen, Anne Tierens, Klaus Beiske, Sverre Heim, Viggo Jønsson

Tidsskr Nor Legeforen 2012; 132: 2056-9

| Tidsskriftet nr. 18/2012 skal det etter forfatternavnene på s. 2056 stå: på vegne av norsk KLL-studiegruppe.

Gruppens deltakere er:

Jakob Dalgaard, Erwin Müller, Johannes Kahrs, Eystein Brandt, Petter Quist-Paulsen, Tom Fjornes, Kjell Sverre Galdal, Per Ole Iversen, Yngve Benestad, Jon Hjalmar Sørbø, Birgitte Dahl Eiken, Robert Brudevold, Yngve Sørum, Marit Rinde, Erik Blichfeldt, Clas Eika, Fredrik Schjesvold, Hoa Thi Tuyet Tran, Waleed Ghanima, Katarzyna Baronowska, Hedda Lerdal, Eva-Marie Jacobsen, Peter Meyer, Einar Haukås, Camilla Stapnes Bjørnsen, Eivind Galteland, Jann Bergheim, Tone Granseth, Vigdis Stenberg, Harald Torsvik, Håvar Knutsen, Johannes Barstad, Anders Waage, Jens Hammerstrøm, Astrid Bergrem, Inger Marie Dahl, Per Blichfeldt, Terje Løitegaard, Lidia Klevstul, Håkon Reikvam, Håvard Solhaug, Solveig Nilsen, Dag Ole Aanderbakk, Roald Lindås, Hildur Nordeng, Jørgen Ibsen, Tor Henrik A. Tvedt, Yngvar Fløisand, Eli Brevig, Steinar Jæger, Gunnar Hopen, Helene Negaard, Jon Lyng, Kjell Teigen, Øystein Fluge.

Vi beklager feilen, den er rettet på nett.

Familiær forekomst av kronisk lymfatisk leukemi i Norge

Geir E. Tjønnfjord, Viggo Jønsson, Bernt E. Ly, Tom Børge Johannesen

Tidsskr Nor Legeforen 2012; 132: 2060-3

I Tidsskriftet nr. 18/2012 skal det etter forfatternavnene på s. 2060 stå: på vegne av norsk KLL-studiegruppe.

Gruppens deltakere er:

Jakob Dalgaard, Erwin Müller, Johannes Kahrs, Eystein Brandt, Petter Quist-Paulsen, Tom Fjornes, Kjell Sverre Galdal, Per Ole Iversen, Yngve Benestad, Jon Hjalmar Sørbø, Birgitte Dahl Eiken, Robert Brudevold, Yngve Sørum, Marit Rinde, Erik Blichfeldt, Clas Eika, Fredrik Schjesvold, Hoa Thi Tuyet Tran, Waleed Ghanima, Katarzyna Baronowska, Hedda Lerdal, Eva-Marie Jacobsen, Peter Meyer, Einar Haukås, Camilla Stapnes Bjørnsen, Eivind Galteland, Jann Bergheim, Tone Granseth, Vigdis Stenberg, Harald Torsvik, Håvar Knutsen, Johannes Barstad, Anders Waage, Jens Hammerstrøm, Astrid Bergrem, Inger Marie Dahl, Per Blichfeldt, Terje Løitegaard, Lidia Klevstul, Håkon Reikvam, Håvard Solhaug, Solveig Nilsen, Dag Ole Aanderbakk, Roald Lindås, Hildur Nordeng, Jørgen Ibsen, Tor Henrik A. Tvedt, Yngvar Fløisand, Eli Brevig, Steinar Jæger, Gunnar Hopen, Helene Negaard, Jon Lyng, Kjell Teigen, Øystein Fluge.

Vi beklager feilen, den er rettet på nett. 